\title{
GLOBALIZATION AND IT: AGENDA FOR RESEARCH
}

\author{
Geoff Walsham \\ University of Cambridge \\ United Kingdom
}

\begin{abstract}
A precise definition of globalization is elusive, but it is widely accepted that the world is becoming increasingly interconnected in terms of its economic, political, and cultural life, and that IT is deeply implicated in the change processes that are taking place. However, these processes are not uniform in their effects. Individuals, groups, organizations, and societies remain distinct and differentiated, and the challenge is to design information systems that enable increased connectivity but also support this inherent diversity. This paper considers the actual and potential contribution of IS research to this challenge, using five levels of analysis ranging from the individual to the societal. Conclusions are drawn on the need for in-depth studies, a broad and evolving research agenda, and an anti-ethnocentric approach.
\end{abstract}

Keywords: Globalization, IS research agenda, levels of analysis, culture

\section{Introduction}

It is widely acknowledged that major social transformations have taken place in organizations and societies over the last few decades, and most commentators believe that the pace of change is unlikely to slow in the foreseeable future. For example, in the last decade, many large organizations have undergone transformation processes, such as delayering and job redefinition, associated with business process reengineering. The

The original version of this chapter was revised: The copyright line was incorrect. This has been corrected. The Erratum to this chapter is available at DOI: 10.1007/978-0-387-35505-4_33 
detailed work life in these organizations, and in small and medium sized enterprises, is often significantly different in style and content to what was the case only a few years earlier. In addition to changes in work and work-life, the norms and values of society outside the sphere of paid employment have also shifted, often dramatically. Attitudes to gender, the environment, race, sex, family life, and religion have been transformed in the latter part of the $20^{\text {th }}$ century in many countries of the world. The term globalization reflects one linking thread for the changes that have taken place. Although hard to define in any precise way, the concept refers to the increasing interconnection of individuals, organizations, and societies in terms of their economic, political, and cultural life.

It is relatively easy to catalogue changes as outlined above, but it is important to remember that there has also been continuity and stability. Societies remain clearly distinct, despite increasing interconnection, and their citizens normally pursue a life-style that would be immediately recognizable to their ancestors of 50 years earlier. Organizations have transformed themselves in many ways, but the human processes involved, for example, in leadership, team working, and the pursuit of personal aspirations remain much the same in essence. Individuals may work or socialize in a different way, and some social norms and values may have shifted, but we all need self-respect, a community or communities to which we belong, and ways of giving meaning to our lives.

The specific role of information and communication technologies in the interweaving of stability and change that has taken place, and that might take place in the future, is the subject of much debate. Some commentators argue that these technologies are the driving forces for change, while others would see them in a more supporting role. It is, however, generally accepted that they are a fundamental element in the changed nature of work processes, in organizational restructuring and in societal transformation. Terms such as the "information society," or even the "information revolution," are relatively common in the academic and business world and are increasingly recognized by the ordinary citizen. However, they often reflect a wide variety of different views on the precise nature of these phenomena, and thus obscure more than they reveal.

In order to investigate the role of information technology in more detail, it is necessary to go down from the level of broad generalizations to the more specific level of organizations, groups, and individuals. However, in doing this, we are confronted with a bewildering array of ever-changing technologies, work processes and organizational forms. Much current debate in business organizations centers around technologies such as groupware, the internet, and enterprise systems, and around topics such as e-commerce and knowledge management, although we can be sure that these will be supplanted in due course by the as-yet-unknown technologies and topics that will be considered central a few years hence.

In addition to the shifting multiplicity of technologies and topics, there are multiple levels at which we can analyze the role of information technology. For example, one can focus at the individual level of personal or professional identity, at the level of teams and group working, at the level of the organization, on interorganizational networks, on a given society, or at the inter-societal level. All these levels can be analyzed separately, but they are, of course, inextricably interconnected.

Much of the literature in the English language that addresses the wide range of issues outlined above has a strong "Western country" bias, both in terms of the subjects of study normally being located in these countries and in terms of the nationalities of the authors. 
However, major economic activity is increasingly taking place in a wider global arena, and what is happening in the countries of Asia, Africa, or Latin America is a subject of concern for the whole world. The cultures of these countries are often radically different to those of the Western countries and insights from work in the latter do not necessarily apply to the former. Japan presents one obvious example of such a difference, and one where significant amounts of published work exist in English. However, much less has been written about, for example, the nature of work and organizations in India or China, that together account for over two billion people.

So, how should we try to make sense of the role played by information technology in this multi-technology, multi-level, multi-cultural arena? Most research in this domain has been carried out by selecting one part of the mosaic and exploring issues in depth in one country, one organization, one group, or even with respect to one individual. This work has provided us with many insights, but the resultant picture of the role of information technology in the contemporary world is highly fragmented, patchy in its coverage, and lacking in overall synthesis. The purpose of this paper is to discuss future research agendas that might help to improve our understanding of IT in the contemporary world. This discussion takes place in the third section. However, prior to that, in the next section, an overall backdrop for the discussion is provided by a brief analysis of the concept of globalization.

\section{What is Globalization?}

The term globalization has achieved the unusual status, in a relatively short time, of becoming fashionable in academic debates in the social sciences, in the business world, and to some extent in the popular media. However, even a cursory examination of these sources demonstrates that the term is highly ambiguous and that it masks a wide variety of opinions on what is happening in the world. The purpose of this section is to summarize and critique some of these views.

Robertson (1992) wrote an influential book on globalization in which he said that "Globalization as a concept refers both to the compression of the world and the intensification of consciousness of the world as a whole" (p. 8).

The first of these two points relates directly to time-space compression, largely mediated by information and communications technologies. The second point is less obvious, and certainly refers to the world as a whole rather than just Western society. The widespread accessibility of communications media such as the television, even in remote rural villages in the Third World or underprivileged urban communities anywhere, means that news of happenings in the world as a whole are available to the great majority of the world's population. This does not necessarily imply a well-informed world, since the "news" are chosen, condensed, filtered, and manipulated by a host of complex mechanisms. However, it does mean that remoteness and isolation are not the same in the contemporary age and that most people are more aware than they were of a wider global arena within which their own community forms only a small part.

Changes in perception and access to wider information sources have significant cultural and political implications, but globalization also refers to important economic 
phenomena. Giddens has joined the globalization theorists in recent years, and he argues that global financial flows are a key element of the globalization process:

Geared as it is to electronic money-money that exists only as digits in computers - the current world economy has no parallels in earlier times. In the new global electronic economy, fund managers, banks, corporations, as well as millions of individual investors, can transfer vast amounts of capital from one side of the world to another at the click of a mouse. As they do so, they can destabilize what might have seemed rock-solid economies-as happened in East Asia. [Giddens 1999]

Global financial flows are one element in trends toward more global business as a whole, although we need to be wary of simplistic generalizations here. Although there is much talk in the business world, and the management schools, of global businesses, global markets, and global supply chains, the degree to which this has occurred to date, and the degree to which it might occur in the future, remains in dispute. For example, Doremus et al. (1998) investigated a range of multinational corporations, mainly in Germany, Japan, and the USA, and argued that such companies, who after all should surely be at the forefront of the move toward globally-minded enterprises, remained tied to approaches derived from their unique national identities:

However lustily they sing from the same hymn book when they gather together in Davos or Aspen, the leaders of the world's great business enterprises continue to differ in their most fundamental strategic behavior and objectives. [Quoted in Kogut 1999]

\subsection{Globalization and Diversity}

This leads on to one of the most controversial issues in the globalization debate, namely the issue of homogenization and diversity. The broad question is whether the globalization phenomena that we have outlined above, such as time-space compression, an increased awareness of the world as a whole, and movements toward global business, will inevitably lead to a decrease in differences among nations, companies, and/or individuals. There is a school of thought, prevalent among the Western business community, for example, which takes this "end of history" idea for granted. The argument runs that there is only one economic system now, capitalism, and that enterprises need to compete globally under this one set of rules. Therefore, all companies that wish to survive will need to adopt the practices of the winners, leading toward more homogeneous ways of doing things and, by extension to the wider society, to a lessdiverse cultural world.

There is some force in this argument, but a range of writers have taken exception to the conclusion of the inevitability of homogenization. For example, Robertson discusses the way in which imported themes are "indigenized" in particular societies, with local culture constraining the receptivity to some ideas rather than others, and adapting them 
all in specific ways. He cites Japan as a good example of this blending of the "native" and the "foreign" as an ongoing process. While accepting the idea of time-space compression facilitated by information technology, Robertson argues that one of its main consequences is an exacerbation of collisions between global, societal, and communal attitudes.

A second example of the counter-argument to the homogenization thesis is provided by Gopal (1997), writing specifically about the developing countries. He argues that the vision of an IT-driven world of progress, efficiency, unlimited markets, individualism, and the superiority of the Western developmental trajectory needs to be challenged, not least because the effects of the use of IT in the West itself have not always been benign. He cites concerns about unemployment, de-skilling, privacy, and surveillance as examples. However, he also argues that each developing country must forge its own path in the future, and not try to imitate inappropriate Western models:

They [developing countries] have different pasts; their historical trajectories have led to different configurations of valences, patterns of trust, responsibilities, and allegiances. They have, as a result, different presents: priorities, voices, capabilities, and capacities are arranged in patterns quite unlike those of the societies from which the technologies originate. And, in spite of the attempts of a few to sediment in the popular imagination a singular vision of prosperous IT-driven existence, they have different imagined futures (Appadurai 1997); their varieties of aspirations and expectations bear little resemblance to the visions embedded in the technology. [p. 140]

Castells (1996) is an influential writer on contemporary society, and his views on globalization echo a number of the above themes, but within a broader conceptualization of the new society that he believes is emerging from current processes of change. He argues that this society is both capitalist and informational, and he defines the latter as follows:

The term informational indicates the attribute of a specific form of social organization in which information generation, processing and transmission become the fundamental sources of productivity and power, because of new technological conditions emerging in this historical period. [p. 21]

Castells believes that globalization is real, in the sense that the markets for goods and services are becoming increasingly globalized. This does not mean that all firms sell worldwide, but that the strategic aim of all firms, large and small, is to sell wherever they can throughout the world, either directly or via their linkage with networks that operate in the world market. However, in the informational economy, there is complex interaction between historically rooted political and social institutions and increasingly globalized economic agents. There is, thus, wide variety in the way in which individual countries and regions act as part of the globalized world. Castells argues that the global 
economy is characterized by its interdependence, but also by its asymmetry, and the increasing diversification within each region.

\subsection{Globalization and Self-identity}

The debate about the extent to which various processes linked to globalization may lead to homogenization in terms of business processes or national cultures rests to a significant extent on the effect of the processes on the individual member of society, whether in the Western or developing world. The argument will be made here that there is no strong evidence of any simple standardization of humanity, and indeed that global forces may, somewhat paradoxically perhaps, have some effects that tend toward the opposite.

Giddens $(1990,1991)$ and Beck (1992) are influential writers about self-identity in contemporary Western society. They both discuss the need for individual life projects, specific to a person's own past history and context, and to his or her future trajectory and aspirations. They argue that the world of relatively set rules, traditions, social classes, and job roles has been undermined. The new, uncertain world requires active navigation. Authors such as these have sometimes been criticized as emphasizing individual freedom of action in societies where the underprivileged can be thought to have little choice. It is certainly true that some people's choices are more constrained than others, and that life chances are very different at birth dependent on one's parentage and background. Nevertheless, any individual growing up and working in the $21^{\text {st }}$ century will need to chart their own course with some vigor, within the range of possibilities available to them, or risk being carried away by the waves of change which will undoubtedly continue to roll.

Robertson talks about this issue related specifically to globalization and he adds a subtle distinction regarding concepts such as life projects themselves, which can be seen to be Western individualistic constructs. More group-oriented societies, such as many of those in Asia, and religions, such as Islam, which place great emphasis on community, would tend not to see the world as composed of distinct individuals with discrete life goals, opportunities, and problems. However, unless one feels that the cultural imperialism of Western individualism will sweep away all this potential resistance, and even then we are back to individualistic life projects, the heterogeneity of these cultural phenomena does not lead us in the direction of individual sameness.

This academic theorizing could be seen to be fiddling while Rome burns. When a large part of the world watches Hollywood movies, it is possible to buy Coca Cola virtually everywhere, and the internet is spreading like wildfire, are we not seeing the Americanization of the world and the end of cultural diversity? It would certainly seem to be the case that more people in the world are exposed to particular influences, such as aspects of American culture as portrayed in films and other media, than has been the case at any time in world history. But there is little evidence that this produces a higher proportion of cultural dopes than in previous eras, and the processes of selective indigenization, due to the collision of external ideas with internal norms and values, may proliferate the production of new hybrids, at the level of the individual, group or society. 


\section{Designing for Diversity: Research Agenda}

The brief discussion in the previous section cannot be used to produce a definitive statement about globalization, nor about the particular role of IT. Nevertheless, three points of connection can be identified that broadly unite the authors cited. First, the contemporary world is undergoing major processes of change that affect all countries of the world and IT is deeply implicated in the changes that are taking place. The change processes will continue to have profound effects on self-identity, the nature of work and employment, organizational structure and networking, and the nature and governance of the nation-state. Second, the change processes are not uniform in their effects and individuals, groups, organizations, and societies will remain distinct and differentiated, although increasingly interconnected. Third, there is an increased need for reflection and action on the part of individuals, groups and societies in order to address issues of global change, including the role that IT plays in this.

If we accept these broad themes regarding globalization and IT, what agendas are implied for information systems designers and academics studying such systems? Is it possible to design systems that enable increased connectivity between individuals, groups, organizations, and societies, but also support the inherent diversity within these categories? The focus of this section of the paper will be on defining research agendas in these various domains, divided into five levels of analysis, ranging from the individual to the societal. At each level, examples of relevant published work are given, the current depth and coverage of work in this domain is discussed, a brief linkage is made to globalization themes, and future IS research agendas are identified. A summary of key points in the section is given in Table 1.

\subsection{Individual}

An example of work in this category is the description by Schultze and Boland (1997) of the work of three systems administrators, Ilana, Dan, and Jon, who were employed by a consulting company called Consultco. They were hired on a contract basis to work for US Co, a large manufacturing firm in a Midwestern U.S. state. The particular work for which they had been hired involved a knowledge management system called KnowMor based on a platform of the groupware Lotus Notes. The responsibility of the system administrators was to set up and operate the system environment to ensure the smooth running of the application in US Co.

Schultze and Boland describe and discuss the perceptions, feelings and actions of the three system administrators, and their search for identity:

We depict these contractors as people struggling to "go on" in a world in which space and place, mind and body, logical and illogical explanations, clean and dirty work, physical and mental activity, and specialized and transcendent knowledge are posed as dualisms. [p. 556] 


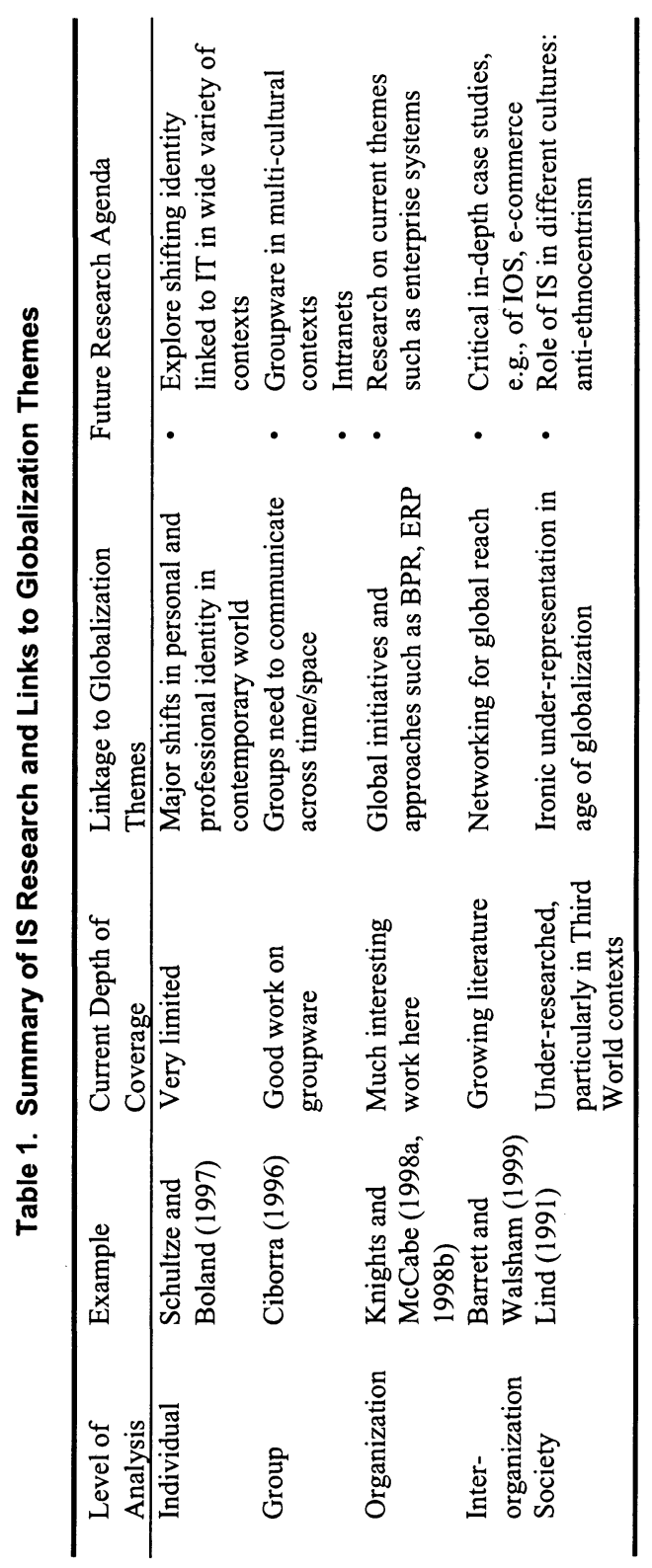


The argument here is that the system administrators felt the need to present their work as involving logical, clean, mental activity based on knowledge that transcends particular places. Such work is contrasted with physical, local, specific work, in which "illogical" things happen and fixes and work-arounds are the norm. However, in practice, the work of Ilana, Dan and Jon involved both types of activity, inextricably intermingled. In terms of personal identity, the system administrators struggled between the selfdisciplining needed to present their work as the former, while often identifying closely with the latter.

It is possible to connect the particular case here with more general globalization themes. The widespread emphasis on core competencies, at least in Western organizations, and the related outsourcing of many tasks previously carried out by permanent employees, has led to a legion of contract workers carrying out activities on a commodity basis. The representation of the work carried out by these people is a key element in determining the price of the commodity. For example, Consultco wished to reinforce the high-level status of their workers by presenting them as being the possessors of transcendent knowledge that is not locally specific and can be seamlessly transferred across space. However, this created pressures in terms of the workers themselves, who had to confront the realities of their work as well as its representation.

Other work on IT and shifting identity includes a case study of health care workers in the UK by Bloomfield and McLean (1996). Walsham (1998) explored the changing identities of particular professional groups, related to new IT, in the banking, insurance, and pharmaceutical industries. Despite such studies, and earlier pioneering work by Zuboff (1988), the topic of shifting identity linked to information technology remains under-researched. The discussion on globalization in this paper emphasized the importance of shifting identity in the contemporary world, but the social theorists on globalization do not go into any detail on individual cases. There are clear agenda here for IS researchers, namely to explore identity linked to new information technology in a wide variety of situations, organizations, and cultures.

\subsection{Group}

The study of the work of groups linked to information technology includes interesting research in the 1990s on groupware. A good example is the book edited by Ciborra (1996). Seven different cases are described in the book, in a variety of U.S. and Western European contexts, and involving a range of organizations and sectors. Ciborra, in the first summary chapter of the book, argues that the development and use of groupware technology in large, complex organizations is variable, context-specific and drifts over time. The book is entitled Groupware and Teamwork: Invisible Aid or Technical Hindrance? Ciborra argues that the question mark remained at the end of the study, since there is no general answer to the question. The very definition of groupware depends on how an organization molds it to the specific context: "'What groupware is' can only be ascertained in situ, when the matching between plasticity of the artefact and the multiform practices of the actors involved takes place" (p. 9).

In addition to the Ciborra book, the literature contains a relatively wide range of other in-depth studies of groupware technology, with Lotus Notes being used in the 
majority of the reported cases, reflecting its relatively dominant market position in groupware technology in the 1990s. For example, Karsten (1999) summarized the results of 17 different applications of Notes reported in the literature. The pressure on organizations to use groupware technology can be seen as a response to globalization trends, requiring individuals, groups, and organizations to communicate across time/space. The use of Lotus Notes by a wide range of organizations could be viewed as a form of homogeneity and standardization. However, the outcomes of the groupware cases were enormously varied, resulting from the complex matching of the plasticity of the technology and the practices of the actors in the specific context. This supports our earlier arguments on the persistence of diversity despite the increased interconnectivity of the world.

What of future agendas for IS research at the group level of analysis? First, a number of the cases reported in the literature cited above mentioned problems with the utilization of groupware where the systems were not restricted to a single country. For example, Orlikowski (1996) described the use of Notes to support incident tracking in the customer support department of a software company called Zeta, with headquarters in the Midwest of the U.S. There is an intriguing reference in the case to difficulties in trying to extend the technology to the three main overseas support offices in the UK, Europe (country not specified), and Australia. However, this aspect of the case was not explored further. In a similar vein, Ciborra and Patriotta (1996) describe a Notes-based application in Unilever designed to support innovation centers that were responsible for the global coordination of specific product categories. The authors note that there were "misunderstandings" due to the introduction of an international environment linking different cultures, but no further analysis is provided. There are clear agendas here for IS researchers to investigate in more detail the role of groupware in multi-cultural contexts.

A second area for future IS research concerns the use of intranets. At the present time, few in-depth case studies of intranets have been published, although research studies are currently taking place. Groupware and intranets are not synonymous, of course, but lessons from the use of groupware can inform our thinking about intranets. For example, the theme of the plasticity of the artefact and its matching to the context is immediately relevant. More specifically, effective intra- or inter-community collaboration, using intranets or groupware, needs a context and climate in which people and groups feel able to share information relatively freely, and where improvisation and change are a permanent and natural part of evolving work process.

\subsection{Organization}

In-depth IS research conducted at the level of the organization is perhaps the best represented of all levels of analysis in the current literature, with many published studies being available (e.g., Orlikowski 1991; Walsham 1993). An example of an interesting recent study, which also addresses wider global agendas, is that reported by Knights and McCabe (1998a, 1998b), concerning a business process reengineering (BPR) case in a medium-sized UK bank, which they called Probank. The bank underwent a series of restructuring initiatives from the late 1980s onward, using telecommunications and online customer database technology, designed to shift customers calls away from local 
branches to centralized back offices. Many customers resented having to contact the back office instead of their local branches. In addition, the "armchair banking" staff were often unable to cope with the volume of calls. In an attempt to address this latter problem, multi-skilled teams were created in the back office, but reactions of staff to this were mixed depending on their earlier job role, with staff whose earlier role involved only the telephone being generally more favorable. Relatively high stress levels remained the norm, however, and operation staff were said to begin "screaming and running about" when "the phone goes wild."

BPR can be seen as one example of global approaches that have affected many organizations across the world. Authors such as Willmott (1994) see BPR as a front for job losses, intensification of work, and tighter management control. What does the Probank case have to say about these issues? Well, certainly there were widespread losses, particularly in the branches. In terms of intensification of work, there appears to have been a more nuanced position, with at least some back office staff feeling that multiskilled teams were a less stressful environment than their previous seven-hour telephone day. Management attempted to tighten control, but there was some evidence of "spaces for resistance" in various forms, some of them quite subtle in terms of the tone and style of staff response to customers. Knights and McCabe (1998a) argued, interestingly, that resistance to new ways of working in change programs such as BPR in Probank is not solely concerned with organizational politics centered on workers' resistance to management or one group trying to achieve advantage over another. It also needs to be thought of in terms of identity relations, or how individuals seek, through political maneuvering, to further or secure their individual careers and identities in an uncertain world. This ties back to issues at the individual level of analysis discussed above.

In terms of future IS research agendas, organization-level studies such as the one reported above are an essential means to get beyond the simple "good" or "bad" label for a new technology or change initiative, technological utopianism or anti-utopianism (Kling 1994), toward a more grounded position based on a range of in-depth studies in particular contexts. A particular example of a current rich vein for IS research is that of enterprise systems. These have largely taken over from BPR as the fashionable large-organization approach to integrated information systems and associated organizational change. There has been an enormous growth in the sales of such systems in the 1990s, with the market leader being SAP at the time of writing. Davenport (1998) quoted estimates of US \$10 billion per year being spent on enterprise systems in 1997/98, which he argued could probably be doubled if consulting expenditures were added. Davenport described "success stories" at various companies such as Elf Atochem, but he also outlined "horror stories" at Mobil Europe, Dell Computers, and Dow Chemicals among others. Davenport provides no detail on these stories, however, and IS researchers could have much to offer in providing such detail. An example of a study which moves further toward this level of detail is that by Hanseth and Braa (1998).

\subsection{Interorganization}

There has been much emphasis in recent years on the partnering of organizations and their interconnection in networks. These initiatives are designed, for example, to exploit 
synergies between partnering organizations, or to improve links with suppliers and customers. They are related to issues of global reach and the striving for increased efficiency and speed of response in rapidly changing markets. Interorganizational information systems (IOS) are often a fundamental part of partnering processes, or the connection of organizations in networks. These systems are increasingly carried over the medium of the Internet, as the scope, familiarity and ease of use of the Net increases.

An example of a specific IOS case study is that by Barrett and Walsham (1999) on the London Insurance Market, which is an important part of the UK general insurance industry, built up around Lloyd's of London. It is a network of hundreds of semiautonomous players, including underwriting groups, brokerage firms and Market managers. Responding to the tough global competitive environment of the insurance industry in the 1990s, the Market has sought to develop and use IT to lower costs by streamlining business processes and to increase service quality and interorganizational efficiency in the Market. Some success was achieved in claims management and settlement systems, and in accounting systems. However, Barrett and Walsham describe how a key system, called the electronic placing system (EPS), encountered many problems and achieved only low levels of adoption and use.

The new EPS system was designed to replace the face-to-face and paper approach to the negotiation and agreement of insurance risk between underwriters and brokers with an electronic system for working at-a-distance. The resistance to the system in the Market can be considered as largely arising from concerns that the new system would undermine the established system of personal trust and relationships and result in a worsening of the competitive position of the London Market rather than the explicit goal of the reverse. Barrett and Walsham conclude that, while electronic trading offers opportunities for speed, efficiency, and the bridging of time and space, complex insurance risks need delicate and sophisticated negotiation, and asynchronous electronic media are not necessarily well-suited to many aspects of this. They also argue that the shift to an electronic placing system places a high value on the explicit representation of knowledge in electronic documents on the network and past information stored in computers. However, these imply uncertain shifts in power-knowledge relations between brokers and underwriters, and resistance to the EPS system could also be seen as reflecting participants' concern regarding their future autonomy, prestige, and control.

There is an extensive and growing literature on IOS (see, for example, Choudhury 1997; Holland 1995) and this can be seen to reflect increased efforts at global reach in the current period. However, there remains a shortage of critical in-depth case studies in this area and the provision of these can be added to our IS research agendas. A crucial area for these future studies is e-commerce or e-business. Despite the enormous hype and interest in the use of the Internet for business-to-business and business-to-consumer applications, it is hard to find in-depth case study material that adopts a critical stance, in the sense of examining the benefits and weaknesses of electronic trading over the Net, viewed from a variety of stakeholder perspectives. The IS research community has a major potential contribution to make in this area. 


\subsection{Society}

Most of the developments in information technology have taken place in Western countries, which themselves display a heterogeneity of culture that is relatively unexplored in the IS literature. But the so-called developing countries are normally even further removed from the contexts in which a particular technology was developed. The mainstream IS community is notable for its almost total disregard of issues of technology transfer and implementation in Third World contexts. However, there is a small body of literature that addresses these issues.

Lind (1991) explored the subject in some depth, using a detailed example of the introduction of a computerized production control system, Copics, into an Egyptian car manufacturing company, Nasco. His basic conclusion was that the model of a production system implicit in Copics was a poor match with the actual functioning of the production system in Nasco, where the rationality was based on Egyptian norms and values. Specific examples of the mismatch included the assumption that users of the computer system will react instantly to problems which arise in their area and will take action to correct things. However, middle-level supervisors and managers were not given the responsibility to do this. Lind argues that systems like Copics are designed around a Western approach to decision making with respect to delegation of authority, whereas in Egypt, decision making tends to be highly centralized. A second example concerns the more uncertain external environment of an Egyptian company, factors that were not present in Copics. These included the availability of imported material, great fluctuations in lead times, and changes imposed by government. Lind summarizes his conclusions as follows:

This book is an attempt to point out how computer programs, developed in the more advanced industrialized countries and based on models and conceptions of reality that are prevailing in these countries, tend to be inappropriate under different conditions in developing countries. The reason, so it is argued in the book, is that models do not have the same explanation value in different cultures. [p. xiii]

Similar themes related to the use of IS in different cultural contexts have been developed by other researchers (see, for example, Malling 1998; Sahay and Walsham 1997). However, this area remains under-researched, doubtless because it is not perceived to affect the richer countries of the world in a direct way. However, there is some irony in this state of affairs, as noted by Castells (1997) in contrasting the age of globalization with the narrow ethnocentricity of much social science:

There is in this book a deliberate obsession with multiculturalism.... This approach stems from my view that the process of technoeconomic globalization shaping our world is being challenged, and will eventually be transformed, from a multiplicity of sources, according to different cultures, histories and geographies....I would like also...to break the ethnocentric approach still dominating much social science at the very moment when our societies have become globally interconnected and culturally intertwined. [p. 3] 
Tricker (1999) supported this anti-ethnocentric approach in the specific domain of IS research and practice. He argued that, as the effects of information management become global, the cultural dimension is not just an interesting attribute of IS development, but is of fundamental significance to its effectiveness.

\section{Conclusions}

This paper has major limitations. The description of the literature on globalization is very selective and brief, as is the attempt to link globalization themes to the five levels of analysis. The paper has not done full justice to the exemplary papers cited, having reduced them to a few paragraphs, and not all streams of IS research are represented. In addition, splitting the IS literature into levels of analysis ignores the fact that the levels are inextricably inter-linked. For example, it is not possible to study shifting personal identity without taking some account of the groups, organizations and society to which the individual belongs. Despite these clear limitations, it is hoped that the main purpose of defining some future research agendas has been achieved. Three general points about these agendas will now be made in conclusion.

First, in order to investigate IS that enable connectivity but support diversity, it is necessary to study particular individuals, groups, organizations, or societies in detail, and in context. Large scale surveys or laboratory experiments may yield interesting data on occasions, but any attempt to study inherent variety, as outlined in the proposed research agendas in this paper, requires methods that go into depth in particular situations. There are a range of ways of approaching this, such as interpretive case studies, ethnographies, or action research projects, but we need to see more of these as a proportion of the totality of IS research in the future.

A second general point is that the IS academic community should focus future research agendas on what is important at the time, and not on some static definition of the "discipline." For example, IS researchers should engage fully with e-commerce at the present time, even though this area cuts across other disciplines such as marketing and strategy. This is not an argument based on simple expediency or short-term fashion. Rather, it is saying that we should engage with the important organizational issues of the current period, bringing to bear what we have learned from earlier topics, but also looking for what is new and different. For example, we learned a lot about groupware in the 1990 s that is relevant to the study of intranets at the current time, but the two research domains are not synonymous.

A final point to end the paper concerns the most striking omission in published IS research in the context of globalization, namely the shortage of serious work on IT in non-Western cultures. In addition, some of the sparse literature in this domain takes culture as an impediment to Western-style "progress," rather than trying to see merit in other cultures' ways of seeing and acting in the world. An understanding of IT in cultures other than one's own can be justified on economic grounds alone, in terms of increased understanding of foreign markets or supply chains, for example. However, a deeper ethical rationale is that we should be concerned with the world as a whole, and not just some subset within which we happen to be located through accident of birth or background. 


\section{References}

Appadurai, A. Modernity at Large: Cultural Dimensions of Globalization. New Delhi: Oxford University Press, 1997.

Barrett, M., and Walsham, G. "Electronic Trading and Work Transformation in the London Insurance Market," Information Systems Research (10:1), 1999, pp. 1-22.

Beck, U. Risk Society: Towards a New Modernity. London: Sage Publications, 1992.

Bloomfield, B. P., and McLean, C. "Madness and Organization: Informed Management and Empowerment," in Information Technology and Changes in Organizational Work, W. J. Orlikowski, G. Walsham, M. R. Jones, and J. I. DeGross (eds.). London: Chapman \& Hall, 1996, pp. 371-393.

Castells, M. The Rise of the Network Society. Oxford: Blackwell Publishers, 1996.

Castells, M. The Power of Identity. Oxford: Blackwell Publishers, 1997.

Ciborra, C. (ed.). Groupware and Teamwork: Invisible Aid or Technical Hindrance? Chichester, UK: Wiley, 1996.

Ciborra, C., and Patriotta, G. "Groupware and Teamwork in New Product Development: The Case of a Consumer Goods Multinational," in Groupware and Teamwork: Invisible Aid or Technical Hindrance?, C. Ciborra (ed.). Chichester, UK: Wiley, 1996, pp. 121-142.

Choudhury, V. "Strategic Choices in the Development of Interorganizational Information Systems," Information Systems Research (8:1), 1997, pp. 1-24.

Davenport, T. H. "Putting the Enterprise into the Enterprise System," Harvard Business Review, January-February 1998, pp. 121-131.

Doremus, P. N., Keller, W. W., Pauly, L. W., and Reich, S. The Myth of the Global Corporation. Princeton, NJ: Princeton University Press, 1998.

Giddens, A. The Consequences of Modernity. Cambridge, UK: Polity Press, 1990.

Giddens, A. Modernity and Self-Identity. Cambridge, UK: Polity Press, 1991.

Giddens, A. Reith Lectures, 1999 (http://news.bbc.co.uk/hi/english/static/events/reith_99).

Gopal, A. "Information Technology and Globalization: Exploring the Underbelly," in Proceedings of Workshop on Understanding Information Technology, Globalization, and Changes in the Nature of Work, University of Alberta, Edmonton, 1997, pp. 135-144.

Hanseth, O., and Braa, K. "Technology as Traitor: Emergent SAP Infrastructure in a Global Organization," in Proceedings of the Nineteenth International Conference on Information Systems, R. Hirschheim, M. Newman, and J. I. DeGross (eds.), Helsinki, Finland, 1998, pp. 188-196.

Holland, C. P. "Cooperative Supply Chain Management: The Impact of Interorganizational Systems," Journal of Strategic Information Systems (4:2), 1995, pp. 117-133.

Karsten, H. "Collaboration and Collaborative Information Technology: What is the Nature of Their Relationship?" in Information Systems: Current Issues and Future Changes, T. J. Larsen, L. Levine, and J. I. DeGross (eds.). Laxenburg, Austria: IFIP, 1999, pp. 231-254.

Kling, R. "Reading 'All About' Computerization: How Genre Conventions Shape Nonfiction Social Analysis," The Information Society (10:3), 1994, pp. 147-172.

Knights, D., and McCabe, D. "When 'Life is but a Dream': Obliterating Politics through Business Process Reengineering," Human Relations (51:6), 1998a, pp. 761-798.

Knights, D., and McCabe, D. “'What Happens When the Phone Goes Wild?': Staff, Stress and Spaces for Escape in a BPR Telephone Banking Regime," Journal of Management Studies (35:2), 1998b, pp. 163-194.

Kogut, B. "What Makes a Company Global," Harvard Business Review, January-February 1999, pp. 165-170.

Lind, P. Computerization in Developing Countries: Model and Reality. London: Routledge, 1991. 
Malling, P. "Information Systems and Human Activity in Nepal," in Implementation and Evaluation of Information Systems in Developing Countries, C. Avgerou (ed.). London: London School of Economics, 1998, pp. 120-128.

Orlikowski, W. J. "Integrated Information Environment or Matrix of Control? The Contradictory Implications of Information Technology," Accounting, Management and Information Technologies (1:1), 1991, pp. 9-42.

Orlikowski, W. J. "Evolving with Notes: Organizational Change Around Groupware Technology," in Groupware and Teamwork: Invisible Aid or Technical Hindrance?, C. Ciborra (ed.). Chichester, UK: Wiley, 1996, pp. 23-59.

Robertson, R. Globalization: Social Theory and Global Culture. London: Sage Publications, 1992.

Sahay, S., and Walsham, G. "Social Structure and Managerial Agency in India," Organization Studies (18:3), 1997, pp. 415-444.

Schultze, U., and Boland, R. J. "Constructing High Tech Space: Mind, Body and Place in Knowledge Work," in Proceedings of the AOS Conference on Accounting, Time and Space, H. K. Rasmussen (ed.). Copenhagen: Copenhagen Business School, 1997, pp. 539-558.

Tricker, R. I. "The Cultural Context of Information Management," in Rethinking Management Information Systems, W. L. Currie and R. D. Galliers (eds). Oxford: Oxford University Press, 1999, pp. 393-416.

Walsham, G. Interpreting Information Systems in Organizations. Chichester, UK: Wiley, 1993.

Walsham, G. "IT and Changing Professional Identity: Micro-Studies and Macro-Theory," Journal of the American Society for Information Science (49:12), 1998, pp. 1081-1089.

Willmott, H. "Business Process Re-engineering and Human Resource Management," Personnel Review (23:3), 1994, pp. 34-46.

Zuboff, S. In the Age of the Smart Machine. New York: Basic Books, 1988.

\section{About the Author}

Geoff Walsham is a Research Professor of Management Studies at the Judge Institute of Management Studies, Cambridge University, UK. His teaching and research is centered on the development, management, and use of computer-based information systems, and the relationship of information and communication technologies to stability and change in organizations and societies. He is particularly interested in the human consequences of computerization in a global context, including both industrialized and developing countries. His publications include Interpreting Information Systems in Organizations (Wiley 1993) and Information Technology and Changes in Organizational Work (edited with Orlikowski, Jones, and DeGross, Chapman \& Hall, 1996). Geoff can be reached by e-mail at g.walsham@jims.cam.ac.uk. 